\title{
COMPARISON OF SIMPLE ALGORITHM DATA (SORTING) CONTROL METHODS ON SELECTION AND BUBBLE SORT
}

\author{
Bustami1, Fadlisyah2, Gusti Alfyansyah, \\ Informatics, Malikussaleh University \\ gustialfyan03@gmail.com1
}

\begin{abstract}
Abstract-In the data there is a sorting process which is sorting data with certain rules, so that it will be arranged in the algorithm. Algorithms are steps that will solve a problem in the data, algorithms have a variety of settlement methods, one of which is the sorting method. Data sorting (Sorting) contains different types such as Bubble Sort, Insertion Sort, Merge Sort, Quick Sort, Selection Sort, and Shell Sort. The following will explain how to process the data sequencing of each method using a simple algorithm, especially in the Selection Sort method, and Bubble Sort.
\end{abstract}

Keywords: Algorithm, Bubble Sort, Selection Sort

\section{Introduction}

Technology plays an important role in everyday life. Programming language is needed in certain needs, because our work at this time always follows technological advancements. For the sake of increasing community satisfaction, the most highlighted side. This of course further strengthens its position as a language of instruction between humans that can be understood, and can be run by a programmer. It has become a part of the life of today's society, not only as a source of information, but also a lifestyle and culture. So that many gamers make programs that facilitate work in the fields of statistics and information, namely in terms of sorting data. 
From the data sorting program there are algorithms that are used to sort a data, one of which is sorting. The advantages of sorting are to facilitate data search, and also so that the data is more systematic because it is ordered. So that the sorting method using sorting is very useful in searching data. Sorting or sorting is the process of compiling elements from random initial inputs into final output arranged in a certain order [4].

\section{Research Methods}

\subsection{Selection Sort Method}

Sorting data with the Selection method can be explained simply by finding the smallest data (Ascending) or searching for the largest data (Discending) from the initial data arrangement from the first data to the last data. After the smallest data is found then exchange it with the first data. After that the smallest data is searched again but starting from the second data to the last data so that the data is in sequence.

According to Abidin [1] the selection sort method is an improvement from the bubble sort method by reducing the number of comparisons. Selection sort is a sorting method by looking for the smallest data value starting from data in position 0 to position $\mathrm{N}-1$. If there are $\mathrm{N}$ data and data collected from the order of 0 to $\mathrm{N}-1$, the sorting algorithm using the selection sort method is as follows:

1) Find the smallest data in $j=0$ to $j=N-1$ intervals.

2) If the smallest data position is found at the postal position, exchange the data in the position of the post with data in position $\mathrm{i}$ if $\mathrm{k}$.

3) Repeat steps 1 and 2 with $j=j+i$ up to $j=N-1$, and so on until $\mathrm{j}=\mathrm{N}-1$.

\subsection{Bubble Sort Method}

This algorithm is a simple sorting algorithm and is usually studied as a subject around sequencing. This Bubble Sort algorithm is a sorting process that gradually moves to the right position because that is called Bubble, which means bubbles. This algorithm 
will sort data from the largest to the smallest (ascending) or vice versa (descending). Simply put, the Bubble Sort algorithm can be defined as sorting by exchanging data with the data next to it continuously until in a certain iteration there is no change. To learn this Bubble Sort algorithm we only need to understand the method used to sort data, simply this algorithm use comparisons in operations between elements [5].

\section{Results and Discussion}

\subsection{Initial Data Table Selection Sort Methods}

Table 1. Preliminary data process the selection sort method

\begin{tabular}{|l|l|l|l|l|l|l|l|l|}
\hline Data & 1 st & 2nd & 3rd & 4th & 5 th & 6th & 7 th & 8th \\
\hline Value & 45 & 25 & 15 & 65 & 55 & 35 & 75 & 5 \\
\hline
\end{tabular}

The first step is looking for the smallest data from the 1st data to the 8 th data from. Found value 5 in the 8 th data. Exchange the value of 5 with a value of 45 in the first data. Next, the second step looks for the smallest data starting from the 2 nd data sequence to the last data. The value of 15 is found in the 3 rd data. Exchange the value of 15 with a value of 25 in the second. Then the third step is found in the value of 25 which is already at number 3 so that there is no exchange of positions with other data. Then the 4th data is not suitable because there is a smaller value in the 6th data, exchange the value 35 with the value of 65 th in the 4 th data. The 5 th data is not suitable because there is a smaller value in the 8 th data. The 6 th data is not suitable because there is a smaller value in the 8th data. The 7 th data is not suitable because there is a smaller value in the 8th data.

Tabel 2. Results Data that has been manually processed by the selection sort method

\begin{tabular}{|l|l|l|l|l|l|l|l|l|}
\hline Data & 1st & 2nd & 3rd & 4th & 5th & 6th & 7th & 8th \\
\hline Value & 45 & 25 & 15 & 65 & 55 & 35 & 75 & 5 \\
\cline { 2 - 9 } & 45 & 25 & 15 & 65 & 55 & 35 & 75 & 5 \\
\cline { 2 - 8 }
\end{tabular}




\begin{tabular}{|l|l|l|l|l|l|l|l|}
\hline 5 & 25 & 15 & 65 & 55 & 35 & 75 & 45 \\
\hline 5 & 25 & 15 & 65 & 55 & 35 & 75 & 45 \\
\hline 5 & 15 & 25 & 65 & 55 & 35 & 75 & 45 \\
\hline 5 & 15 & 25 & 65 & 55 & 35 & 75 & 45 \\
\hline 5 & 15 & 25 & 65 & 55 & 35 & 75 & 45 \\
\hline 5 & 15 & 25 & 35 & 55 & 65 & 75 & 45 \\
\hline 5 & 15 & 25 & 35 & 45 & 65 & 75 & 55 \\
\hline 5 & 15 & 25 & 35 & 45 & 55 & 75 & 65 \\
\hline 5 & 15 & 25 & 35 & 45 & 55 & 65 & 75 \\
\hline
\end{tabular}

Data has been sorted in ascending order. To get the reverse data sequence in descending, that is, the order of the largest data to the smallest data, enough to change the value of the data being searched into the largest data.

\subsection{Initial Data Table Bubble Sort Method}

Table 3. Preliminary data on the process of the bubble sort method

\begin{tabular}{|l|l|l|l|l|l|l|l|l|}
\hline Data & 1 st & 2nd & 3rd & 4 th & 5 th & 6th & 7 th & $8^{\text {th }}$ \\
\hline Value & 45 & 25 & 15 & 65 & 55 & 35 & 75 & 5 \\
\hline
\end{tabular}

Compare the first data with the second data, if the first data is bigger than the second data, then exchange places. In the first comparison the value of 45 is greater than the value of 25 . Then compare the second data with the third data, if the second data is greater than the third data, then exchange places. In the second comparison the value of 45 is greater than the value of 15 . Compare the 3rd and 4th data there is no change in the order because the value of 45 is smaller than the value of 65 so that the data arrangement is fixed. Compare the 4 th and 5 th data, there is a change in the order because the value of 65 is greater than the value of 55. Compare the 5th and 6th data, there is a change in the order because the value of 65 is greater than the value of 35. Data 6th and 7 th there is no change in the order because the value of 65 is smaller 
than the value of 75 . The 7 th and 8 th data changes occur because the value of 75 is greater than the value of 5 .

Table 4. Data on the process of the bubble sort method

\begin{tabular}{|l|l|l|l|l|l|l|l|l|}
\hline Data & 1 st & 2nd & 3rd & 4 th & 5 th & 6 th & 7 th & 8 th \\
\hline Value & 45 & 25 & 15 & 65 & 55 & 35 & 75 & 5 \\
\cline { 2 - 9 } & 45 & 25 & 15 & 65 & 55 & 35 & 75 & 5 \\
\cline { 2 - 9 } & 25 & 45 & 15 & 65 & 55 & 35 & 75 & 5 \\
\cline { 2 - 9 } & 25 & 45 & 15 & 65 & 55 & 35 & 75 & 5 \\
\cline { 2 - 9 } & 25 & 15 & 45 & 65 & 55 & 35 & 75 & 5 \\
\cline { 2 - 9 } & 25 & 15 & 45 & 65 & 55 & 35 & 75 & 5 \\
\cline { 2 - 9 } & 25 & 15 & 45 & 55 & 65 & 35 & 75 & 5 \\
\cline { 2 - 9 } & 25 & 15 & 45 & 55 & 35 & 65 & 75 & 5 \\
\cline { 2 - 9 } & 25 & 15 & 45 & 55 & 35 & 65 & 75 & 5 \\
\cline { 2 - 8 } & 25 & 15 & 45 & 55 & 35 & 65 & 5 & 75 \\
\hline
\end{tabular}

After comparing all data from the 1st to the 8th data in stages, it turns out that the data order has not been sorted, so the process continues until the data is actually sorted. Compare again the data has been processed before.

Table 5. Continued data on the bubble sort method process have not been sequenced

\begin{tabular}{|l|l|l|l|l|l|l|l|l|}
\hline Data & 1 st & $2^{\text {nd }}$ & 3rd & 4 th & 5 th & 6th & 7 th & 8 th \\
\hline Value & 25 & 15 & 45 & 55 & 35 & 65 & 5 & 75 \\
\hline
\end{tabular}

The first data with the second data, if the 1st data is bigger the 2nd data, then exchanging places. In the first comparison the value of 25 is greater than the value of 15. Compare the second and third data, there is no change in the order because the value of 25 is smaller than the value of 45 . Compare the 3rd and 4th data, there is no change in order because the value is 45 small from the value of 55. Compare the 4th and 5th data, there is a change in the order because the value of 55 is greater than the value of 35 . Compare the 
5 th and 6 th data there is no change in the order because the value of 55 is greater than the value of 65 . Data on the 6th and 7th changes in the order because the value of 65 is greater than the value of 5 .

Table 6. Data on the process of the bubble sort method

\begin{tabular}{|l|l|l|l|l|l|l|l|l|}
\hline Data & 1st & 2nd & 3rd & 4th & 5th & 6th & 7th & 8th \\
\hline Value & 25 & 15 & 45 & 55 & 35 & 65 & 5 & 75 \\
\cline { 2 - 9 } & 15 & 25 & 45 & 55 & 35 & 65 & 5 & 75 \\
\cline { 2 - 9 } & 15 & 25 & 45 & 55 & 35 & 65 & 5 & 75 \\
\cline { 2 - 9 } & 15 & 25 & 45 & 55 & 35 & 65 & 5 & 75 \\
\cline { 2 - 8 } & 15 & 25 & 45 & 35 & 55 & 65 & 5 & 75 \\
\cline { 2 - 8 } & 15 & 25 & 45 & 35 & 55 & 65 & 5 & 75 \\
\cline { 2 - 8 } & 15 & 25 & 45 & 35 & 55 & 5 & 65 & 75 \\
\hline
\end{tabular}

After comparing all data from the 1st to the 8th data in stages, it turns out that the data order has not been sequenced as well, so the process continues until the data is actually sorted. Compare again the data has been processed before.

Table 7. Data on the process of the bubble sort method has not been sorted

\begin{tabular}{|l|l|l|l|l|l|l|l|l|}
\hline Data & 1 st & 2nd & 3rd & 4th & 5 th & 6th & 7th & 8th \\
\hline Value & 15 & 25 & 45 & 35 & 55 & 5 & 65 & 75 \\
\hline
\end{tabular}

Compare the 1st and 2nd data, there is no change in the order because the value of 15 is smaller than the value of 25. Compare the 2nd and 3rd data, there is no change in the order because the value of 25 is smaller than the value of 45 . Compare the 3 rd data and fourth there is a change in the order because the value of 45 is greater than the value of 35 . Compare the 4 th and 5 th data there is no change in the order because the value of 45 is smaller than the value of 55. Compare the 5th and 6th data occurs change in order because the value of 55 is greater than the value of 5 . 
Table 8. Data on the process of the bubble sort method

\begin{tabular}{|l|l|l|l|l|l|l|l|l|}
\hline Data & 1st & 2nd & 3rd & 4th & 5th & 6th & 7th & 8th \\
\hline Value & 15 & 25 & 45 & 35 & 55 & 5 & 65 & 75 \\
\cline { 2 - 9 } & 15 & 25 & 45 & 35 & 55 & 5 & 65 & 75 \\
\cline { 2 - 9 } & 15 & 25 & 35 & 45 & 55 & 5 & 65 & 75 \\
\cline { 2 - 9 } & 15 & 25 & 35 & 45 & 5 & 55 & 65 & 75 \\
\hline
\end{tabular}

For the comparison of the 6th and 7th data, the 7th and 8th data data do not exchange because they are sorted. For comparison of the 1st and 2nd data, the 2nd and 3rd data, the third and fourth data lastly do not exchange data. Next, the 4 th data and 5th data are exchanged because 45 is greater than 5 . For the comparison of the 5 th and 6th data, the 6th and 7th data, the 7th and 8th data are not exchanged for comparison of 1st and 2nd data, 2nd and 3rd data, data does not exchange. Then the $3 \mathrm{rd}$ data and 4 th data are exchanged because 35 is greater than 5 .

Table 9. Advanced data on the process of the bubble sort method

\begin{tabular}{|l|l|l|l|l|l|l|l|l|}
\hline Data & 1st & 2nd & 3 rd & 4 th & $5^{\text {th }}$ & 6 th & 7 th & 8 th \\
\hline Value & 15 & 25 & 35 & 45 & 5 & 55 & 65 & 75 \\
\cline { 2 - 9 } & 15 & 25 & 35 & 45 & 5 & 55 & 65 & 75 \\
\cline { 2 - 9 } & 15 & 25 & 35 & 5 & 45 & 55 & 65 & 75 \\
\cline { 2 - 9 } & 15 & 25 & 35 & 5 & 45 & 55 & 65 & 75 \\
\cline { 2 - 9 } & 15 & 25 & 35 & 5 & 45 & 55 & 65 & 75 \\
\cline { 2 - 9 } & 15 & 25 & 5 & 35 & 45 & 55 & 65 & 75 \\
\hline
\end{tabular}

For comparison of the 4 th and 5 th data, the 5 th and 6 th data, the 6 th and 7 th data, the 7 th and 8th data last. Because the data has not been sequenced we do the previous process again.

Table 10. Continued process of the bubble sort method

\begin{tabular}{|l|l|l|l|l|l|l|l|l|}
\hline Data & 1 st & 2nd & 3rd & 4 th & 5th & 6th & 7th & 8 th \\
\hline Value & 15 & 25 & 5 & 35 & 45 & 55 & 65 & 75 \\
\hline
\end{tabular}


For comparison of the 1st and 2nd data, the data does not exchange, because the previous data is smaller than the data afterwards. Then the second data and the third data are exchanged because 25 is greater than 5 . For the comparison of the $3 \mathrm{rd}$ and 4 th data, the 4 th and 5 th data, the 5 th and 6 th data, the data 6 and 7 , the last 7 th and 8th data can be seen not exchanging data, because the previous data is smaller than the data afterwards. Because almost sequential data we do the previous process again. For comparison of the 1st and 2nd data, the data is exchanged, because the value of 15 is greater than the value of 5 .

Table 11. Data on the manual results of the final process

\begin{tabular}{|l|l|l|l|l|l|l|l|l|}
\hline Data & 1 st & 2nd & 3rd & 4 th & 5 th & 6 th & 7 th & 8 th \\
\hline Value & 15 & 25 & 5 & 35 & 45 & 55 & 65 & 75 \\
\cline { 2 - 10 } & 15 & 25 & 5 & 35 & 45 & 55 & 65 & 75 \\
\cline { 2 - 9 } & 15 & 5 & 25 & 35 & 45 & 55 & 65 & 75 \\
\cline { 2 - 9 } & 15 & 5 & 25 & 35 & 45 & 55 & 65 & 75 \\
\cline { 2 - 9 } & 5 & 15 & 25 & 35 & 45 & 55 & 65 & 75 \\
\hline
\end{tabular}

Until this step the data is in order, but if not then the comparison process and place conversion can be done until the last step by staying comparing the first and second data so that the data obtained in full order from the smallest to the left and the most to the right. The data is in ascending order. To get the descending data order by descending, the order of the largest data to the smallest data, simply by changing the value of the data being searched to be the largest data.

\section{Conclusions}

Sorting data is indeed quite diverse, but in this journal we only use 2 methods, namely bubble sort and selection sort. Thus in the process the fastest method of the two methods above is selection sort compared to the bubble sort method which takes a lot of time in the final process. Of course these 2 methods have their own 
strengths and weaknesses. With a comparison of these simple algorithms, it is expected to be easier in finding the right method in solving each problem that involves the data sorting process.

\section{Bibliography}

[1] Abidin, Taufik Fuadi. 2008. Struktur Data. Informatika. Universitas Syah Kuala Banda Aceh.

[2] Arief, H.S., Desi, Windi Sari., 2012, Analisis Urutan Penyisipan, Algoritma Urutan Gabung dan Implementasinya dalam Bahasa Pemrograman $\mathrm{C}++$. Infotel Volume 4 Jurnal Nomor 2 November 2012

[3] Eko, N.W., 2009., Algoritma Sederhana dalam Penyortiran Data. DINAMIK Jurnal Teknologi Informasi Volume XIV, No.1, Januari 2009: 14-22

[4] Rachmat, Abdullah. 2016. Makalah Algoritma Penyortiran. https://11101.ilearning.me/2016/11/08/makalahalgoritmasorti ng-rachmat-abdullah/, diakses pada 15 Agustus 2018.

[5] Riswan, Abidin. 2016. Mempelajari Bubble Sort Algorithms for Ordering. https://teknojurnal.com/pengertian algoritmabubble-sort/, Diakses pada 15 Maret 2019. 